\title{
Case Report \\ Delayed-Onset Seizure in a Mild Quetiapine Overdose: Report of a Case and Review of the Literature
}

\author{
Jason A. Chen $(\mathbb{D}$, Katherine M. Unverferth, and Erick H. Cheung $\mathbb{1}$ \\ Department of Psychiatry and Biobehavioral Sciences, UCLA David Geffen School of Medicine, Los Angeles, CA 90095, USA \\ Correspondence should be addressed to Erick H. Cheung; ehcheung@mednet.ucla.edu
}

Received 11 February 2018; Revised 26 March 2018; Accepted 10 April 2018; Published 15 May 2018

Academic Editor: Erik Jönsson

Copyright (C) 2018 Jason A. Chen et al. This is an open access article distributed under the Creative Commons Attribution License, which permits unrestricted use, distribution, and reproduction in any medium, provided the original work is properly cited.

\begin{abstract}
Among atypical antipsychotics, quetiapine is commonly prescribed and considered to have a favorable side effect and safety profile. Here, we report the case of a patient who developed a generalized tonic-clonic seizure 28 hours following ingestion of $1,400 \mathrm{mg}$ of quetiapine. Review of the literature identifies delayed-onset seizure as a potential complication of quetiapine overdose. Unique to this case, delayed-onset seizures occurred in a patient with a relatively low dose of quetiapine and no obvious toxidrome, suggesting that this reaction may be an important consideration in the management of quetiapine overdose. The pharmacokinetics and pharmacodynamics of quetiapine may explain this unusual phenomenon.
\end{abstract}

\section{Introduction}

Quetiapine is an atypical antipsychotic that possesses low to moderate antagonist activity at multiple neurotransmitter receptors, including serotonergic 5-hydroxytryptamine (5$\left.\mathrm{HT}_{2 \mathrm{~A}}\right)$ receptors, dopaminergic $\left(\mathrm{D}_{1}\right.$ and $\left.\mathrm{D}_{2}\right)$ receptors, histaminergic $\left(\mathrm{H}_{1}\right)$ receptors, and adrenergic $\alpha_{1}$ and $\alpha_{2}$ receptors, and partial agonism at $5-\mathrm{HT}_{1 \mathrm{~A}}$ receptors [1]. Quetiapine has become widely used for a variety of indications because of its favorable side effect and safety profile, notably with decreased incidence of extrapyramidal symptoms compared to other antipsychotics. Patients with an acute overdose of quetiapine may demonstrate central nervous system depression, sinus tachycardia, prolonged QTc interval, hypotension, coma, and seizures [2-4]. We report a case of quetiapine overdose accompanied by a delayed-onset seizure, a rare and poorly understood complication.

\section{Report of a Case}

A 21-year-old woman was brought to the emergency department (ED) 22 hours after reporting an intentional ingestion of $1,400 \mathrm{mg}$ of quetiapine. She had also consumed approximately 5 drink equivalents of alcohol. Within a few hours of her overdose, she became somnolent and slept for 19 hours until the next morning. When she awoke, the patient attended an outpatient psychiatry appointment where she disclosed her overdose and was subsequently brought to the ED. At the time of the ED evaluation, she denied any ongoing symptoms resulting from the overdose. Her daily medications were verified as $300 \mathrm{mg}$ of bupropion XL and $50 \mathrm{mg}$ of quetiapine, and her typical alcohol consumption was 2 drink equivalents per week. The patient had started quetiapine 4 days previously as part of a regimen for major depressive disorder; she did not have a known history of psychosis or manic symptoms and was previously quetiapine naïve. She denied a history of previous seizures.

In the $\mathrm{ED}$, her vital signs were stable, with temperature at $36.9^{\circ} \mathrm{C}$, blood pressure at $121 / 85$, heart rate at 95 beats/minute, and respiratory rate of 16 breaths/minute. Her weight measured 80 kilograms. On examination, she was alert and oriented with no focal neurological deficits. A 12-lead ECG was unremarkable and her urine toxicology screen was negative for amphetamines, barbiturates, benzodiazepines, cannabinoids, cocaine, methadone, opiates, oxycodone, and ethanol. A basic metabolic panel and liver function panel were within normal limits. From the ED, she was deemed medically stable and admitted to the inpatient psychiatry ward.

In the psychiatry ward, six hours after presentation to the ED (thus approximately 28 hours after overdose), the patient experienced a generalized tonic-clonic seizure that 
was witnessed by a nurse, lasting 30 seconds and resolving spontaneously. Immediately following the seizure episode, the patient was somnolent with altered mental status. Initially, she was unable to state her name or current whereabouts and reported feeling confused and drowsy. She exhibited sinus tachycardia (130 beats/minute), temperature of $37.9^{\circ} \mathrm{C}$, and QTc interval of $438 \mathrm{~ms}$; computed tomography of the brain without contrast was normal. Prolactin level was noted to be mildly elevated at $28.3 \mathrm{ng} / \mathrm{ml}$ (reference range: $3-23.1 \mathrm{ng} / \mathrm{ml}$ ). She was transferred to the medicine service for further monitoring, whereupon magnesium sulfate was administered and her postictal symptoms gradually resolved over several hours. An awake electroencephalography (EEG) was performed 23 hours postseizure and showed no evidence of epileptiform activity or other abnormalities. No additional seizure activity was noted during her stay. The remainder of her course was uncomplicated until her discharge 8 days later.

\section{Discussion}

Delayed or late-onset seizure is a rare complication of quetiapine overdose and has been reported in two previous case studies. Young et al. [5] reported a case of a 27-year-old woman who ingested $30 \mathrm{~g}$ of quetiapine and who had two generalized tonic-clonic seizures after 24 hours, each lasting less than 1 minute and treated with lorazepam and propofol. Yam et al. [6] described a 31-year-old man who ingested $4 \mathrm{~g}$ of quetiapine and was found unresponsive at home, presenting with a Glasgow Coma Scale score of 3. Twenty-seven hours following ingestion, he had a generalized tonic-clonic seizure lasting 45 seconds, treated with lorazepam and phenytoin. The unique aspect of this reported case includes the lower dose of quetiapine $(1,400 \mathrm{mg})$, with fewer accompanying signs and symptoms of overdose.

The delayed-onset seizure is curious because its pathophysiology is difficult to explain. First, the presence of seizure is only a rare side effect of quetiapine overdose, even at relatively high doses. A chart review from the California Poison Control System database noted seizures in 22 of 945 of patients who had overdosed on quetiapine [3]. Second, the delayed occurrence of a seizure following overdose incident is peculiar in light of the pharmacokinetics of quetiapine. Other reports of seizure place the timing at 4-8 hours following quetiapine overdose [2,7]. Plasma concentration of quetiapine typically peaks at $1-1.5$ hours, and its elimination half-life is approximately 6 hours $[8,9]$. Therefore, after 28 hours, quetiapine is present at less than $5 \%$ of its maximum plasma concentration. Delayed-onset seizures have also been rarely reported with overdose of other drugs with similar pharmacokinetic properties, for example, 13 hours after ingestion of $400 \mathrm{mg}$ of citalopram [10], 9 hours after $6.75 \mathrm{~g}$ of bupropion extended release [11], up to 24 hours in a large series of bupropion XL overdoses [12], and 19 hours after ingestion of an unknown amount of amitriptyline [13]. However, these examples demonstrate a shorter interval than reported in our case and in other instances of quetiapine overdose.

This case provides new insight into the toxicity of quetiapine. Seizures, though a rare complication of atypical antipsychotic overdose, may be caused by blockade of $\mathrm{D}_{2}$ receptors [14], histamine receptors [15], $\gamma$-aminobutyric acid $\left(\mathrm{GABA}_{\mathrm{A}}\right)$ receptors, adrenergic receptors, and hypoxia [16]. Compared to other atypical antipsychotics (and in general, typical antipsychotics), quetiapine has a higher binding affinity to $\mathrm{H}_{1}$ receptors and a lower affinity for $\mathrm{D}_{2}, 5-\mathrm{HT}_{1 \mathrm{~A}}$ and $5-\mathrm{HT}_{2 \mathrm{~A}}$ receptors $[17,18]$. Given this spectrum of receptor binding affinities, we speculate that blockade of histamine receptors may mediate the delayed-onset seizures of quetiapine, although it is probable that this phenomenon arises out of interactions between receptor types. The action of quetiapine at these receptors may occur on longer time scales compared with plasma clearance. For example, the receptor occupancy half-life for $\mathrm{D}_{2}$ receptors was estimated at 10 hours, and the $5-\mathrm{HT}_{2}$ effective occupancy half-life has been estimated at 27-64 hours $[9,19]$. These properties may explain the unusual observation of delayed seizures in quetiapine overdose long after the peak plasma drug concentrations.

A limitation of this study is the generalizability of the patient's presentation to others with quetiapine overdose; therefore we considered other possible etiologies of seizure. The patient was young and healthy, without electrolyte abnormalities or structural defects on neuroimaging. Though she was regularly taking bupropion $\mathrm{XL}$, a drug known to lower the seizure threshold, her dose was moderate $(300 \mathrm{mg})$ and previously well-tolerated and therefore was unlikely to cause seizures. However, a contribution to quetiapine toxicity cannot be ruled out. Her alcohol use was also relatively low, and acute withdrawal was unlikely. Furthermore, the plasma concentration of quetiapine was not measured in this patient; therefore, it is unclear whether the patient's clearance or metabolism of quetiapine was abnormal. Indeed, the slight elevation in serum prolactin level at time of presentation may point to prolonged persistence of quetiapine. Future measurement of plasma quetiapine levels in patients presenting late may clarify the relationship between pharmacokinetics and late-onset seizures.

In this case, we report the occurrence of a delayedonset seizure 28 hours following quetiapine overdose in the amount of $1,400 \mathrm{mg}$. Together with previous reports in the literature, this case illustrates the rare potential for delayed-onset seizures that may correlate with the unusual pharmacokinetics of quetiapine, providing new insight into pathophysiology. We suggest that providers who are evaluating or managing patients following quetiapine overdose should consider the possibility that the patient may be at risk for seizures for 24 hours (or longer), even in the absence of other symptoms of acute toxicity.

\section{Conflicts of Interest}

The authors declare that they have no conflicts of interest.

\section{References}

[1] A. Schotte, P. F. M. Janssen, W. Gommeren et al., "Risperidone compared with new and reference antipsychotic drugs: in vitro and in vivo receptor binding," Psychopharmacology, vol. 124, no. 1-2, pp. 57-73, 1996. 
[2] C. R. Balit, G. K. Isbister, L. P. Hackett, and I. M. Whyte, "Quetiapine Poisoning: A Case Series," Annals of Emergency Medicine, vol. 42, no. 6, pp. 751-758, 2003.

[3] A. Ngo, M. Ciranni, and K. R. Olson, "Acute Quetiapine Overdose in Adults: A 5-Year Retrospective Case Series," Annals of Emergency Medicine, vol. 52, no. 5, pp. 541-547, 2008.

[4] F. Eyer, R. Pfab, N. Felgenhauer, T. Strubel, B. Saugel, and T. Zilker, "Clinical and analytical features of severe suicidal quetiapine overdoses - A retrospective cohort study," Clinical Toxicology, vol. 49, no. 9, pp. 846-853, 2011.

[5] A. C. Young, K. C. Kleinschmidt, and P. M. Wax, "Late-onset seizures associated with quetiapine poisoning," Journal of Medical Toxicology, vol. 5, no. 1, pp. 24-26, 2009.

[6] M. F.-C. Yam, C.-F. Kiew, and C.-P. Chong, "Hyperglycemia and late onset seizures associated with quetiapine overdose," Tzu Chi Medical Journal, vol. 25, no. 2, pp. 119-121, 2013.

[7] M. Bodmer, T. Burkard, O. Kummer, R. Beyrau, S. Krähenbühl, and M. Haschke, "Pharmacokinetics and pharmacodynamics of quetiapine in a patient with a massive overdose," Therapeutic Drug Monitoring, vol. 30, no. 4, pp. 553-556, 2008.

[8] N. G. M. Hunfeld, E. M. Westerman, D. J. Boswijk, J. A. M. De Haas, M. J. A. M. Van Putten, and D. J. Touw, "Quetiapine in overdosage: A clinical and pharmacokinetic analysis of 14 cases," Therapeutic Drug Monitoring, vol. 28, no. 2, pp. 185-189, 2006.

[9] C. Lindsay DeVane and C. B. Nemeroff, "Clinical pharmacokinetics of quetiapine: an atypical antipsychotic," Clinical Pharmacokinetics, vol. 40, no. 7, pp. 509-522, 2001.

[10] K. M. Engebretsen, C. R. Harris, and J. E. Wood, "Cardiotoxicity and late onset seizures with citalopram overdose," The Journal of Emergency Medicine, vol. 25, no. 2, pp. 163-166, 2003.

[11] G. Shepherd, L. I. Velez, and D. C. Keyes, "Intentional bupropion overdoses," The Journal of Emergency Medicine, vol. 27, no. 2, pp. 147-151, 2004.

[12] P. Starr, W. Klein-Schwartz, H. Spiller, P. Kern, S. E. Ekleberry, and S. Kunkel, "Incidence and onset of delayed seizures after overdoses of extended-release bupropion," The American Journal of Emergency Medicine, vol. 27, no. 8, pp. 911-915, 2009.

[13] M. Levine, D. E. Brooks, A. Franken, and R. Graham, "Delayedonset seizure and cardiac arrest after amitriptyline overdose, treated with intravenous lipid emulsion therapy," Pediatrics, vol. 130, no. 2, pp. e432-e438, 2012.

[14] K. Burke, C. J. Chandler, B. S. Starr, and M. S. Starr, "Seizure promotion and protection by D-1 and D-2 dopaminergic drugs in the mouse," Pharmacology Biochemistry \& Behavior, vol. 36, no. 4, pp. 729-733, 1990.

[15] H. Yokoyama and K. Iinuma, "Histamine and Seizures: Implications for the Treatment of Epilepsy," CNS Drugs, vol. 5, no. 5, pp. 321-330, 1996.

[16] M. Levine and A.-M. Ruha, "Overdose of atypical antipsychotics: Clinical presentation, mechanisms of toxicity and management," CNS Drugs, vol. 26, no. 7, pp. 601-611, 2012.

[17] J. S. Markowitz, C. S. Brown, and T. R. Moore, "Atypical antipsychotics part I: Pharmacology, pharmacokinetics, and efficacy," Annals of Pharmacotherapy, vol. 33, no. 1, pp. 73-85, 1999.

[18] W. K. Kroeze, S. J. Hufeisen, B. A. Popadak et al., "H1-histamine receptor affinity predicts short-term weight gain for typical and atypical antipsychotic drugs," Neuropsychopharmacology, vol. 28 , no. 3, pp. 519-526, 2003.

[19] O. Gefvert, M. Bergström, B. Långström, T. Lundberg, L. Lindström, and R. Yates, "Time course of central nervous
dopamine-D2 and 5-HT2 receptor blockade and plasma drug concentrations after discontinuation of quetiapine (Seroquel ${ }^{\circledR}$ ) in patients with schizophrenia," Psychopharmacology, vol. 135, no. 2, pp. 119-126, 1998. 


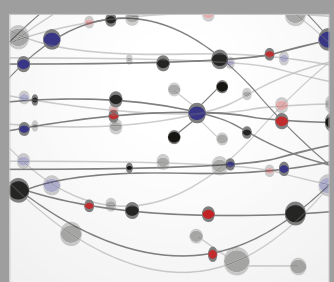

The Scientific World Journal
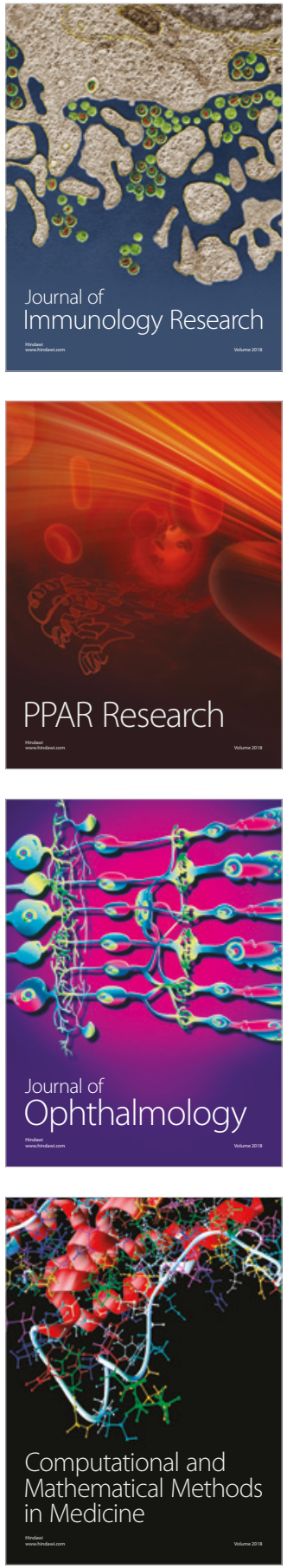

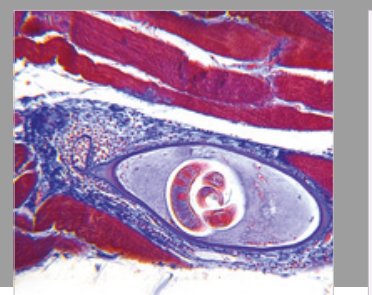

Gastroenterology Research and Practice

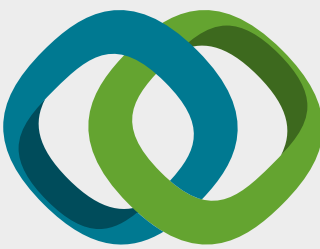

\section{Hindawi}

Submit your manuscripts at

www.hindawi.com
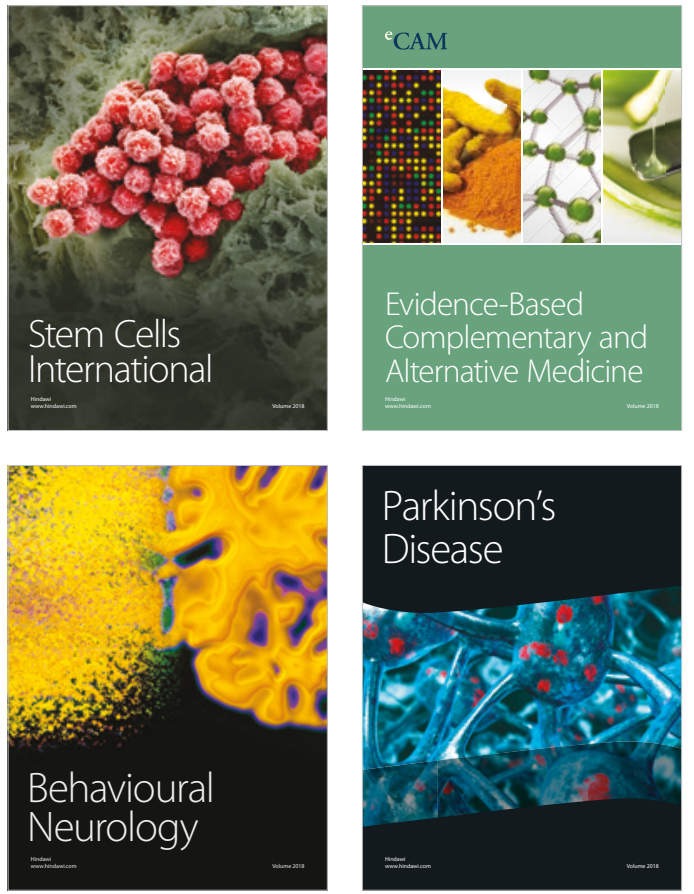

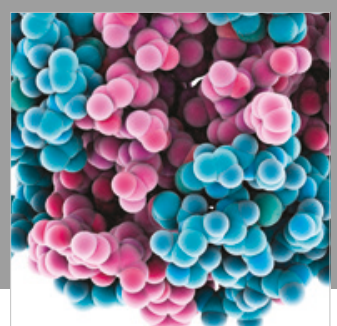

ournal of

Diabetes Research

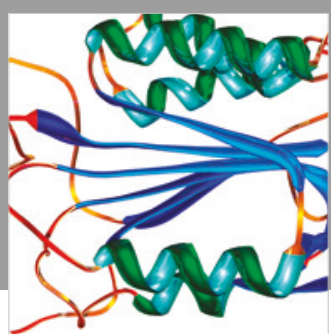

Disease Markers
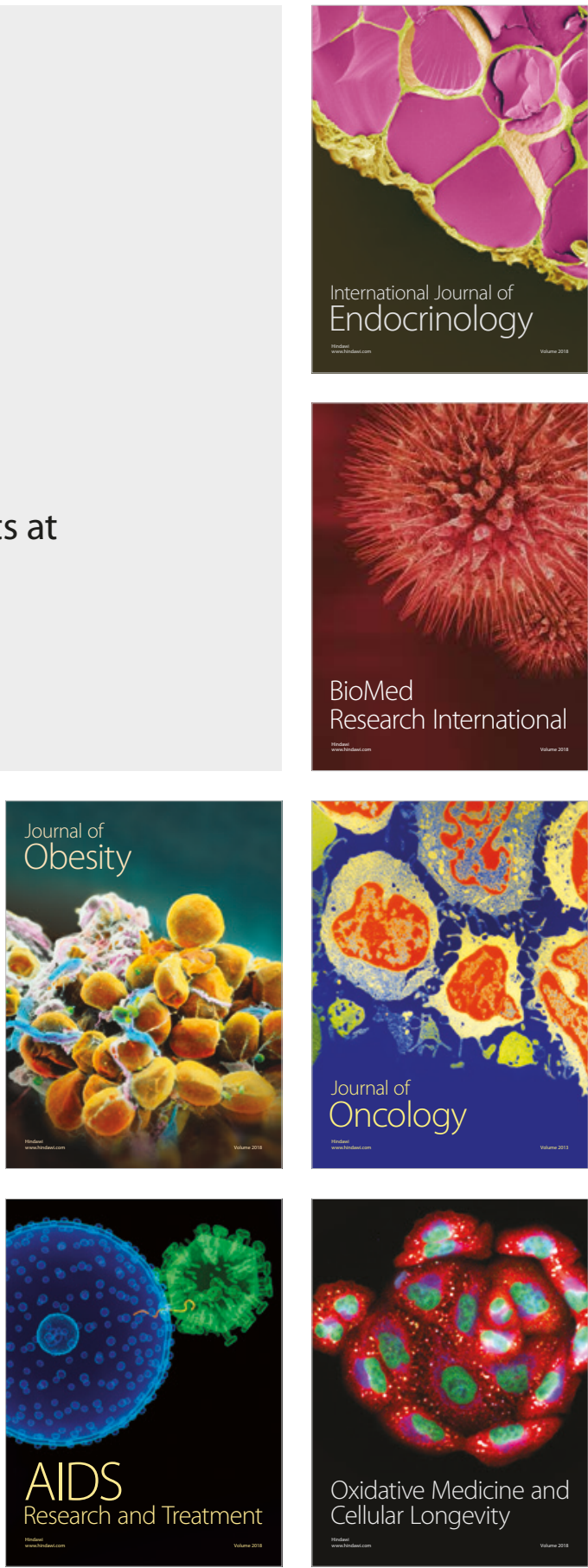